\title{
Exploring Sumba woven textile motifs through a digital technique using the Escher method
}

\author{
M. Rosandini \& J. Samuel \\ Telkom University, Bandung, Indonesia
}

\begin{abstract}
East Sumba traditional woven textiles are East Indonesian textile artifacts. They have considerable visual potential because of their ornaments and motif patterns. This article explores the transformation of the East Sumba motif pattern through digital art techniques. Using digital experimentation with the Escher-types repeats method, innovative and varied new patterns were produced to meet the fashion industry's needs. As a result, four new digital patterns were created. The most effective Escher techniques for exploring non-geometric forms are translation, reflection, and glide reflection. The further development of the East Sumba-Escher digital motif will enhance the various artwork on surface pattern textiles and fashion designs.
\end{abstract}

Keywords: digital art, Escher, exploration, motif, Sumba

\section{THEORETICAL BACKGROUND}

\subsection{Introduction}

Sumba woven motif patterns are inspired by the Sumba community and its environment, which are then distilled into decorative ornaments. Stilation is a changing the shape of an object in nature into an artistic form or a particular style (Nizam 2019). The characteristics of Sumba weaving motif patterns are geometric and non-geometric shapes. The ornaments on the East Sumba Ikat woven fabric are dynamic with their inspiration coming from natural, non-geometric decoration in the form of humans, flora, and fauna. According to Kartiwa (2007), Sumba ornaments are inspired by nature, and are usually in the form of animals such as horses and chickens.

The horse ornament symbolizes courage, unity, authority, and the nature of a noble. The horse's motif on Sumba's ikat weaving is often depicted by the horse's character swinging its legs back and forth, where this pose symbolizes the courage and nature of a warrior (Kartiwa 2007). The ornamental chicken variety is used in Sumba ikat because these animals are often used in ritual ceremonies to tell fortune. Therefore, chicken represents leadership and unity. Chicken motifs are usually in the form of male roosters with the comb's characteristic that symbolizes virility (Kartiwa 2007). From that explanation, we can see the enormous potential of Sumba woven ornaments from their decorative shapes and the value of meaning that lies within them.

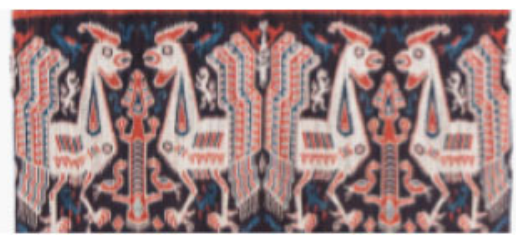

Figure 1. East Sumba Ikat woven textile. 
However, despite its great potential, many designers and researchers utilize the Sumba woven textile to develop and use its decorative shapes as the inspiration for products, especially for the surface motif patterns in digital techniques.

Some research that leads us to the utilization of East Sumba woven textiles was conducted by Ningsih (2019) that wrote about the utilization of the textiles through fashion for urban people. Ningsih (2019) used natural woven textiles. The innovation appeared on the function and form of its original woven textile, the result of which was a collection of fashion wear. On the other hand, Indonesian surface pattern designer Fika Julia, with her brand byfikajulia in 2016, produced textile printing inspired by motif patterns from East Sumba woven textiles. The textiles were then applied to ready-to-wear fashion. She used a digital technique to compose the shapes of Sumba motifs, with some simple repeat patterns. The motifs that Julia produced has a more modernpop look because she was targeting young people. Based on Julia's motif pattern observation, it was discovered that she was using simple, seamless, repeat patterns, such as half-drop and brick repeat patterns (Kight 2011). However, to make motifs, there are many ways to create innovation. Therefore, digital techniques for developing patterns utilizing Sumba ornaments still need to be developed to produce a greater variety of forms.

\subsection{Initial conceptual framework}

Chun (2011) said that digital technology development is rapidly exercising influence across all fields, including contemporary art. He applied new concepts, values, tools, and methods. Based on the authors' observation, research of traditional motif pattern development using advanced techniques is limited. In fact, some of artists are still using conventional repeat pattern techniques, such as square repeat or half-way repeat (half-drop and brick repeat pattern) (Kight 2011), which therefore brings out the usual pattern composition. There is a potential repeat pattern technique, the Escher Repeat Type, which could be applied to any non-geometric form to make an innovative composition. The Escher Repeat Type is usually used for artwork, considering its original form was from M.C. Escher's graphic art masterpiece, but the principle of making the composition could be applied to digital surface pattern design as well.

M.C. Escher was a graphic designer who used mathematics in the making of his works. The tessellation technique that Escher introduced, or commonly called the Escher technique, was inspired by the beautiful and intricate arrangement of tiles in architecture in Alhambra, Spain. However, the elements forming its patterns were only limited to geometric shapes, so Escher tried to make tessellation using living objects such as birds, fish, and horses. One of Escher's works that used tessellation techniques is "The Horseman" with its constituent element being a man who is riding a horse (Taschen 2009).

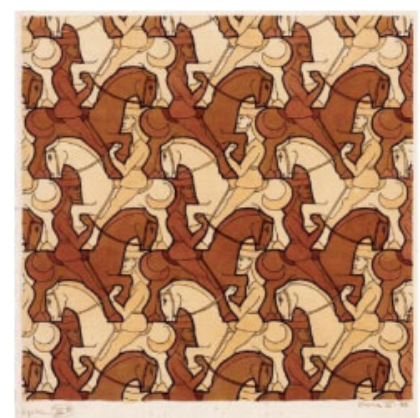

Figure 2. "The Horseman”, Escher's masterpiece.

Between the Sumba motif and Escher artwork, similarities were found in their characteristics. Both process non-geometric shapes and have mathematical elements, so there is good potential 
that can be developed by combining them. The form of non-geometry in the variety of Sumba ikat weaving is another potential source of inspiration for developing motif patterns using the Escher technique. Therefore, it is possible to create an innovative motif form, inspired by the variety of ornamental Sumba woven textiles, using the Escher-Repeat technique with digital work, to be applied to fashion products. This digital method was included in the characteristic of digital art, perfectly duplicability (Chun 2011), in which all substances abstracted into "bits" in the digital world, making it possible to create a perfect and infinite duplication of the original product/artwork.

\section{METHOD}

\subsection{Quantitative method}

The method used in this study was a mixed-method, namely qualitative and quantitative. The quantitative method was used because in processing motifs using Escher techniques, some calculations were needed since Escher techniques are mathematics. Literature study was done to collect information on the Escher-Repeat types from various sources including books and journals.

\subsection{Qualitative method}

The qualitative method was used because this research focused on exploring the techniques used. In terms of finding out the motif patterns' characteristics, the observations on the Sumba woven textile and Escher's artwork and techniques were done. The visual observation was done by seeing each motif's details and comparing the design elements of both objects. To make the new form of motifs, some digital explorations were undertaken to find the innovative structure. The digital experimentation method, applying the Escher technique using the graphic software design, consists of four methods: translation, reflection, rotation, and glide reflection, inspired by Sumba ikat weaving patterns such as chickens, horses, deer, and dragons. This visual exploration aimed to find new advanced form of motif pattern. There were three steps of exploration: (1) Initial exploration: specify the shapes from East Sumba ornaments. In this step, the chicken and horse forms were chosen since they are common, and the Escher-Repeat technique was mastered.

(2) Advanced experiment: applying East Sumba ornament with Escher-Repeat by producing modules.

(3) Arranging the modules into seamless repeating composition.

\section{RESULTS}

\subsection{Initial and advanced exploration results}

Initial exploration was carried out to understand the Escher technique. The experiments applied were translation, reflection, rotation, and glide reflection. The four methods used objects found in the ornamental variety of Sumba ornament shapes. The result of the process was the motif modules. In advanced exploration, colors and more detailed elements were added into the motif modules. The use of virtual texture elements (invented texture) was done by making a square geometrical arrangement in the coloring process and providing details that aimed to imitate the actual texture inspiration (real texture) on Sumba woven textiles because of the intersection points of warp and weft. By using contrasting colors, it became more dynamic and brought up the harmony and balance patterns. The best results were presented on the table below. The translation and glide-reflection method are the most optimal form and produce the best visual from this experiment. The advanced exploration was aimed to create the tessellation formed composition from the motif modules, then it automatically seamlessly repeats. 
Table 1. Results of initial and advanced exploration.

\begin{tabular}{lll}
\hline Visual inspiration & Initial exploration module & Advanced exploration \\
\hline & &
\end{tabular}
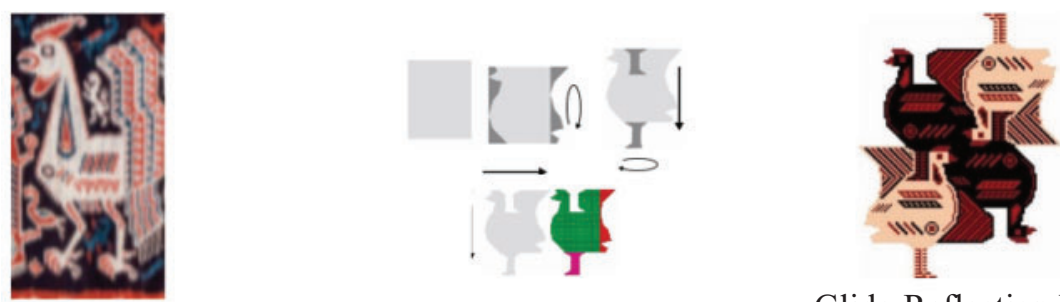

Glide-Reflection Method
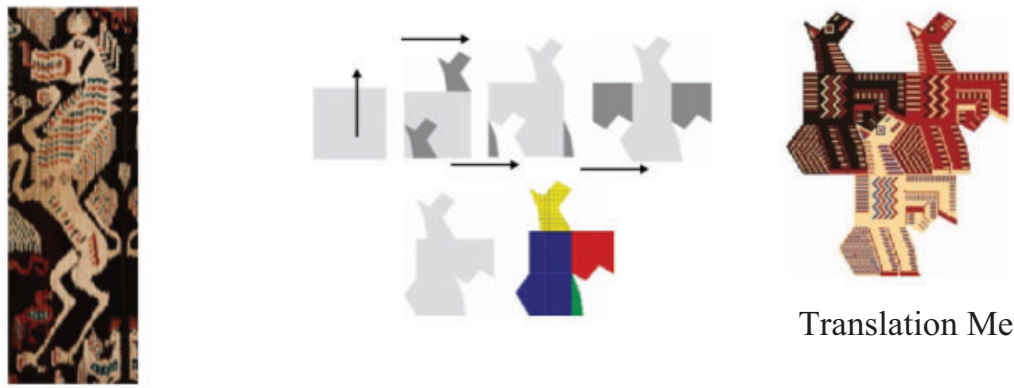

Translation Method
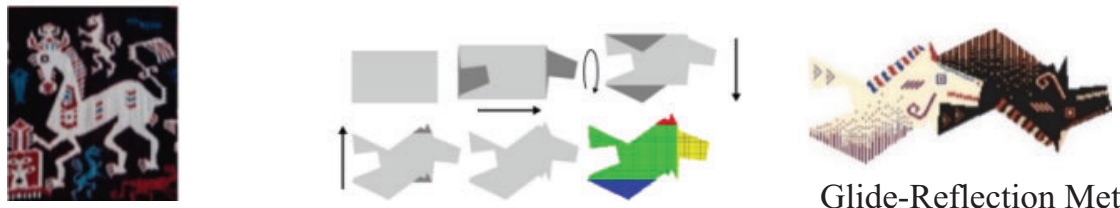

Glide-Reflection Method

\subsection{Digital seamless Escher-repeat of sumba woven textile}

The next step after the tessellation module formed was making a seamless composition. It was automatically formed after the module from the initial exploration finished. The seamless repetition was made in the $15 \times 15-\mathrm{cm}^{2}$ size. As seen below, the composition is seamless, dynamic, and still has the characteristics of Sumba ornaments.

\section{DISCUSSION}

Based on experiments, the digital approach using Escher type should begin with (1) determine the basic geometry shape, (2) develop basic geometry shape into the typical form of visual reference 

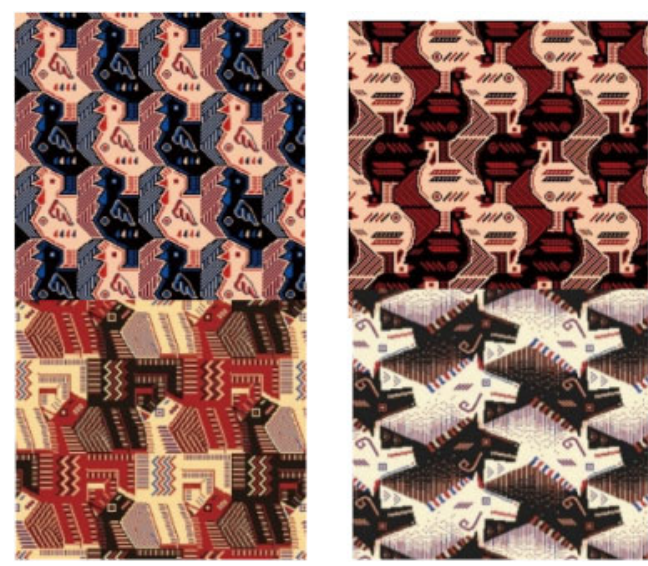

Figure 3. Results of seamless Eshcher-Repeat of Sumba woven textile.

silhouette (in this case, horse and chicken forms of Sumba ornament) considering the Escher principles become one module, then (3) seamlessly repeat the motif module, and (4) complete the step with color rendering and detail and finally the arrangement of motifs in accordance with the method in the Escher technique applied.

The innovations that emerged from these experiments are: (1) the new composition form of Sumba ornaments, from the one flat single pattern to a seamless repeat pattern by using the EscherRepeat method. But still have traditional Sumba characteristic forms: the horse and chicken shapes; and (2) the digital techniques, and the results of this research are more complex than the last existing modern product. The complexity can be seen in the interlace pattern structure and the details inspired by the Sumba motif elements such as lines and dots.

\section{CONCLUSIONS}

This research aims to produce more innovative motif pattern forms by utilizing the typical East Sumba woven textile ornaments through digital techniques. The innovation of the motif pattern was made with the Escher-Repeat method, using four principles: translation, reflection, glide-reflection, and rotation. The best visual form of this research was formed by the translation and glide-reflection method. There is an aesthetic value addition on the visual of the East Sumba motif patternpreviously in the form of fabric sheets that were mainly made with a woven technique - becoming digital and seamless forms that are more dynamic and can be applied to fashion contemporary industries. This digital approach is the beginning of the textile and fashion revolution. Using the digital method to develop some traditional visual forms could lead us to further research on information technology utilization in motif pattern making for contemporary fashion design.

\section{REFERENCES}

Chun, J.H. 2011. A review of the Characteristics of Digital Art Expressed in Contemporary Fashion. International Journal of Fashion Design, Technology and Education 4(3):161-171.

Kartiwa, S. 2007. Tenun Ikat : Ragam Kain Tradisional Indonesia. Jakarta: Gramedia Pustaka Utama.

Kight, K. 2011. A Field Guide to Fabric Desig., Stash Books, Lafayette.

Ningsih, Y.S. 2019. Revitalization f Sumba Woven into Fashion Product for Urban People as a Target Market. Serat Rupa Journal of Design 3(1):61-76.

Nizam, A. 2019. Viabilitas Ragam Hias Sulur Gelung Teratai. Jurnal Corak: Jurnal Seni Kriya 8(2).

Taschen. 2009. M. C. Escher: The Graphic Work. New York: Barnes \& Noble, Inc. 